\title{
The Course Module Division Based on MOOCs
}

\author{
Xueguang Li, Ying Xu, Weihong Zhao, Junpeng Yu, Shuren Zhang, Weina Liu, Yi Gao and Shukun \\ Wang \\ College of Mechanical and Electrical Engineering, Changchun University of Science and \\ Technology , Changchun 130022 \\ Lixueguang@cust.edu.cn, lixg_1979@163.com
}

Key words:MOOCs; online course; open course; course modules division.

\begin{abstract}
With the development of online courses, open courses, MOOCs(Massive Open Online Courses) develops also and becomes more popular now, in this paper, the background of MOOCs was analyzed, questionnaire survey was accomplished aimed at "Mechanical manufacturing technology" course, according to the survey result, the classroom was divided into six districts based on physical position, the course also was classified into different modules, this paper takes the "position error analysis and computation for the part positioned by inner hole surface " as example to illustrate, the contents was classified into two modules, the teaching and studying effect is better than the normal teaching method, next, this method should applied on all the contents of this course.
\end{abstract}

\section{Introduction}

Nowadays, many universities all over the world build Open course, online course which have close relation to MOOCs[1-3], Yale university built the open course website based on internet, the provides some course for students to study like humanities, social science, physics and biological science. The rapid explosion of Massive Open Online Courses (MOOCs) has recently beentempered by critiques focused on the alienating and isolated student experience[4].The classic teaching, learning mode and contents should be adjusted to fulfill the demanding of MOOCs[5-6]. The students can browse open course resource, no credit, no academic degree, no any certification, only provide the platform and all kinds of resource for students, the target is provide service for more people in addition to the students in campus, to open the course resource to society to meet the demanding of lifelong learning and different group, moreover, each person could build their own study schedule according to their own circumstance. There are video resources correspond to each course, through the course website, people could search the teaching teacher. Harvard University, MIT, New York University all carried out the open courses.

Nowadays, the international top online education platform developed in China, some Chinese education resource sharing platform develops fast also, the wall of classic university was broken. In such circumstance, the name of high level university should be known all over the world by the high quality education resource, they also have chance to choose the excellent students in more wide range based MOOCs platform. Accordingly, the low level university should face the destiny that be eliminated if they do not try to improve their education quality. Hence, the MOOCs has very important meaning, Fig. 1 shows the developed speed of MOOCs. 


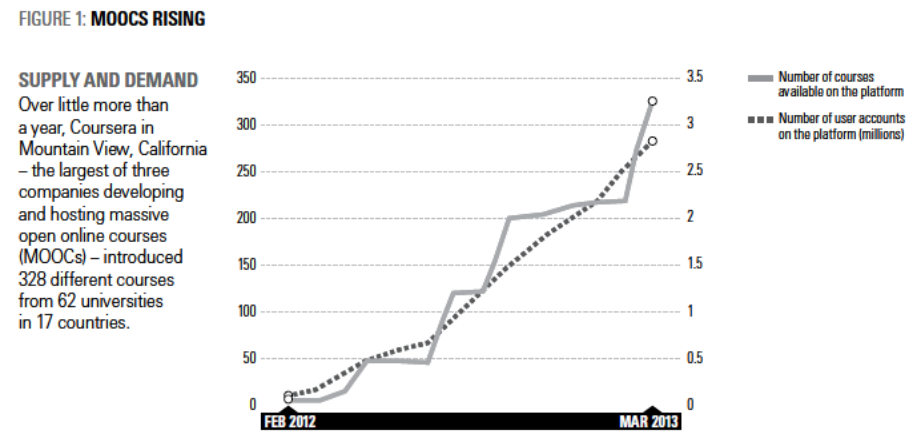

Fig.1 developed speed of MOOCs(Sourc e: Adapted by permission from Macmillan Publishers Ltd: Nature (Waldrop, M.M., 'Online Learning: Campus 2.0’, 13 March, 2013).)

\section{2 . Investigation and Survey}

This paper takes Changchun university of science and technology as example, questionnaire about MOOCs was finished among the students major in mechanical design, manufacturing and automation, the result shows 52 percent students who agree adopting MOOCs type to teach, 23 percent students who agree that the MOOCs is proper for the optional course and 17 percent students who do not agree adopting the MOOCs and online courses type to teach, 8 percent students take neutral attitude about the MOOCs and online courses, the result as shown in Fig.2.

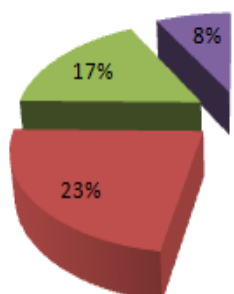

Fig.2 questionnaire result

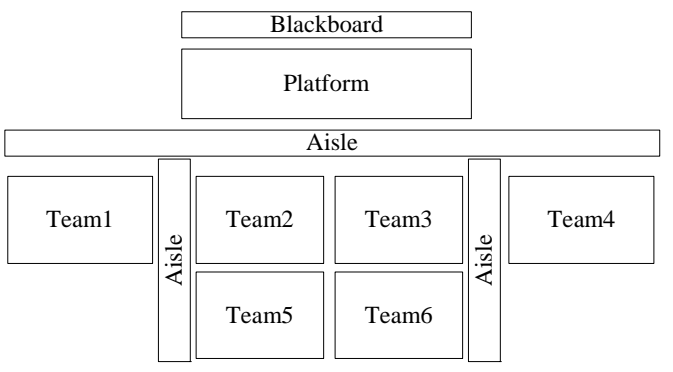

Fig.3 physics position division

According to the questionnaire result, the two classes which were taught by author were divided into six learning groups, the total number of students is sixty, ten students for each group, there is a leader for each group who should administrate the group, in the classroom, six physics position division were made for six learning groups, as shown in Fig.3.

The usual performance and homework should be assigned according to different group. This kind of learning group motivate the students to learn and has better learning, in this paper, takes the course of mechanical manufacturing technology as example, the contents of position error analysis and calculation were taught based on MOOCs mode.

\section{The Course Module Division Based on MOOCs}

For the reason that the course should be taught based on MOOCs mode, the contents of the course need to be broken into different modules, on one side it should keep consecutiveness for different modules, on another side it should keep independence for the single module, so we should not teach course according to the classic mode and type. Different module should be shown to the students independent . In this paper, we take the course of mechanical manufacturing technology as example, the course difficulties are about the content of position error analysis and calculation, through analysis, this part could be reduced to two calculation methods, steps calculation method and direct calculation method, each method includes two circumstance, position error computation when the work piece is fixed by inner hole or outer surface, hence, four modules were made for this 
part, each part is about twenty minutes long. Compare with the classic teaching method, the learning result is better.

\section{Position error teaching based on MOOCs}

The content of position error analysis and computation is important and difficult, for student it is too difficult to understand better, when we analyze the position error, we should calculate the base location inaccuracy error $\Delta_{j b}$ and position basis movement error $\Delta_{j w}$, then according to the equation $\Delta_{d w}=\Delta_{j b} \pm \Delta_{j w}$ to calculate the position error $\Delta_{d w}$. the base location inaccuracy error is generated because of position basis does not coincide with process basis, which equal to the biggest change range of process basis relative to position basis in the direction of process dimension. Position basis movement error is generated because of the manufacturing error of position basis surface, position part and tolerance clearance between location couple, which equal to the biggest change range between position basis and its ideal location in the direction of process dimension. In this paper, takes the position error analysis and calculation as example which was divided into four modules, the position error analysis and calculation for the part which is fixed by inner hole includes two modules.

4. 1 MOOCs module(1): position error calculation for work piece which is positioned by inner hole based on steps calculation method

The process diagrammatic drawing as shown in Fig.4. The process dimension is A in Fig.4(a) and the process dimension is B in Fig.4(b).

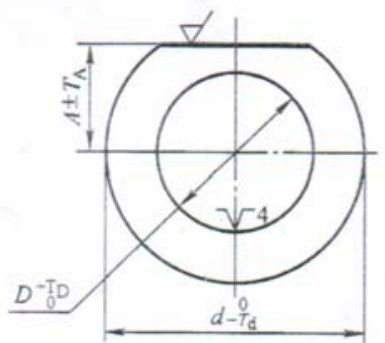

(a)

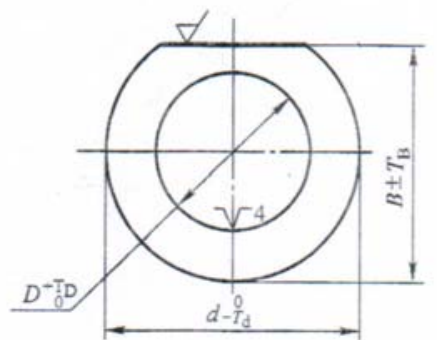

(b)

Fig.4 Process diagrammatic drawing

\section{1) Position basis coincides with process basis}

(1) Horizontal position pin

When the position pin is placed in horizontal direction, the work piece is fixed on the pin, due to the gravity, work piece hole contact with the top generatrix of pin, the hole center position $\mathrm{O}$ exists under the pin center position O1, as shown in Fig.5(a).

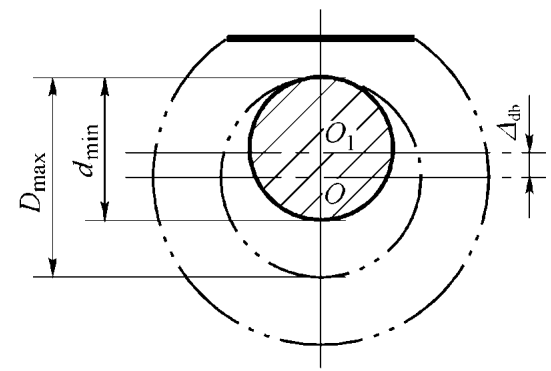

(a)

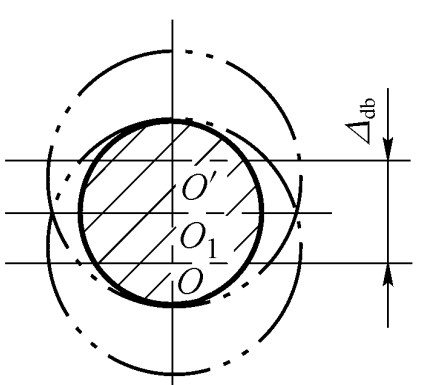

(b)

Fig. 5 work piece is positioned by inner hole, the process basis is the hole center line 
In such circumstance,

$$
\begin{aligned}
& \Delta_{j w}=O O_{1}=\frac{1}{2}\left(D_{\text {max }}-d_{\text {轴min }}\right) \\
& D_{\text {max }}=D_{\text {min }}+T_{D} \\
& d_{\text {pin-min }}=d_{\text {pin-max }}-T_{\text {pin }}
\end{aligned}
$$

Hence $\Delta_{j w}=\frac{1}{2}\left[D_{\min }+T_{D}-\left(d_{\text {pin-max }}-T_{\text {pin }}\right)\right]=\frac{1}{2}\left(T_{D}+T_{\text {pin }}+\Delta s\right)$

$\Delta \mathrm{S}=D_{\text {min }}-d_{\text {pin-max }}$

$\Delta_{d w}=\Delta_{j b}+\Delta_{j w}=\frac{1}{2}\left(T_{D}+T_{\text {pin- }}+\Delta s\right)$

(2) Vertical position pin

When the position pin is placed in vertical direction, the work piece is fixed on the pin, work piece hole contact with the top or bottom generatrix of pin, so the hole center position $\mathrm{O}$ may exist two sides of the pin center position, as shown in Fig.5(b).

In such circumstance,

$\Delta_{j w}=o o^{\prime}=20 o_{1}=T_{D}+T_{p i n}+\Delta s$

$\Delta_{d w}=\Delta_{j b}+\Delta_{j w}=T_{D}+T_{p i n}+\Delta s$

\section{2) Position basis does not coincide with process basis}

The work piece is fixed on the pin, position basis does not coincide with process basis, the process diagrammatic drawing as shown in Fig.4(b)

$\Delta_{j b}=T_{d} / 2$

(1) Horizontal position pin

$$
\begin{aligned}
& \Delta_{j w}=\frac{1}{2}\left(T_{D}+T_{\text {pin }}+\Delta s\right) \\
& \Delta_{d w}=\Delta_{j b}+\Delta_{j w}=\frac{T_{d}}{2}+\frac{1}{2}\left(T_{D}+T_{\text {pin }}+\Delta s\right)
\end{aligned}
$$

(2) Vertical position pin

The work piece is fixed on the pin, position basis does not coincide with process basis.

$$
\begin{aligned}
& \Delta_{j b}=T_{d} / 2 \\
& \Delta_{j w}=T_{D}+T_{\text {pin }}+\Delta s \\
& \Delta_{d w}=\Delta_{j b}+\Delta_{j w}=\frac{T_{d}}{2}+\left(T_{D}+T_{\text {pin }}+\Delta s\right)
\end{aligned}
$$

4. 2 MOOCs module(2): position error calculation for work piece which is positioned by inner hole based on direct calculation method

For this module, it is not necessary to calculate the base location inaccuracy error $\Delta_{j b}$ and position

basis movement error $\Delta_{j w}$, but calculate the position error $\Delta_{d w}$ directly, which equal to the biggest change range between process basis and its ideal location in the direction of process dimension. By comparing with module(1) and module(2), students could understand better, the process diagrammatic drawing as shown in Fig.4(b)

2) Position basis does not coincide with process basis

(1) Horizontal position pin 

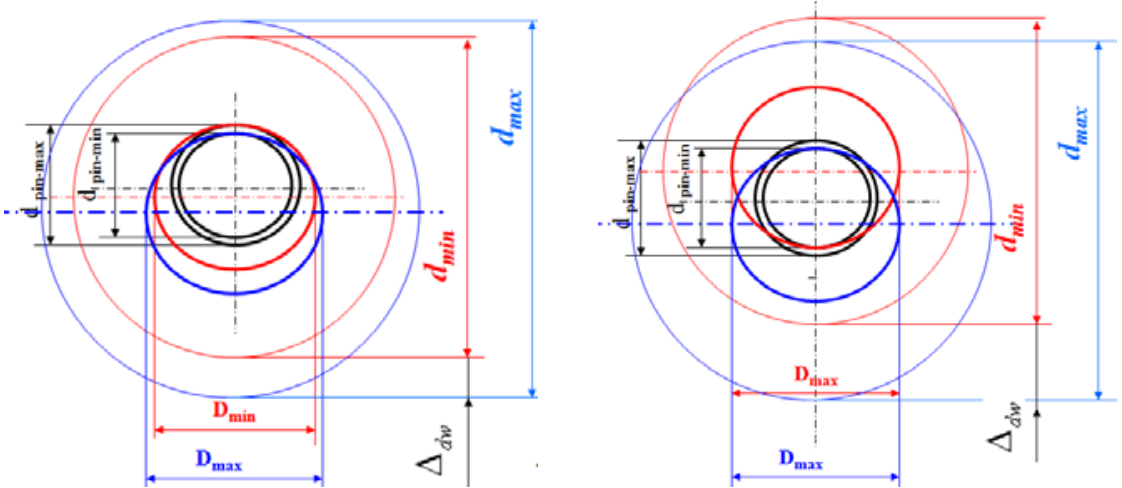

Fig.6 position error analysis

According to the principle that the position error equals to the biggest change range between process basis and its ideal location in the direction of process dimension, the position error analysis result could be shown in drawing as Fig.6(a).

$$
\Delta_{d w}=T_{d} / 2+\left(T_{D}+T_{\text {pin }}+\Delta \mathrm{s}\right) / 2
$$

(2) Vertical position pin

The position error analysis result also could be shown in drawing as Fig.6(b) according to the principle that the position error equals to the biggest change range between process basis and its ideal location in the direction of process dimension.

$$
\Delta_{d w}=T_{d} / 2+T_{D}+T_{\text {pin }}+\Delta_{s}
$$

\section{Summary}

In sum, take the "position error calculation for work piece which is positioned by inner hole" as example, the content was divided into two modules, the experiment shows that the learning result is better, the contents become easy to understand by build MOOCs modules. The internet+ era is coming, the reform of higher education is imperative, the reform includes teaching method, teaching content, teaching mode, the MOOCs has the era characteristic. The teaching mode of the class in university also changes gradually, the role and function of teacher in the class changes too, however, no matter what happened, the target is to create a new way for students to learn effectively and conveniently.

\section{References}

[1]Dalit Levy. Lessons Learned from Participating in a Connectivist Massive Online Open Course (MOOC), Proceedings of the Chais conference on instructional technologies research 2011: Learning in the technological era,31-36.

[2] Stephen J. Marshall, MERLOT Journal of Online Learning and Teaching, 2013, 9(2):216-227.

[3] Siemens, G., (2012, July 25). MOOCs are really a platform. eLearnspace. Retrieved from: http://www.elearnspace.org/ blog/2012/07/25/moocs-are-really-a-platform/

[4] Kaitlin Clinnin. Redefining the MOOC: Examining the multilingual and community potential of massive online courses, Journal of Global Literacies, Technologies, and Emerging Pedagogies, 2014,2(3) :140-162

[5] Sui Fai John Mak, Roy Williams, Jenny Mackness. Blogs and Forums as Communication and Learning Tools in a MOOC, Proceedings of the 7th International Conference on Networked 
Learning, 2010, 275-284.

[6] Enoch, J., (2012). Claiming access to elite curriculum: Identification and division at the harvard annex. Journal of Curriculum Studies, 44(6):787-808. 